\title{
Proteinograma sérico de bezerros holandeses do nascimento até um ano de vida*
}

\section{Blood serum proteinogram of holstein calf from birth until one year old}

\author{
Francisco Leydson Formiga Feitosa, ${ }^{\star \star}$ Eduardo Harry Birgel, ${ }^{\star \star \star}$ Regina Mieko Sakata Mirandola, ${ }^{\star \star \star}$ \\ Sílvia Helena Venturoli Perri**
}

\begin{abstract}
Resumo
Para determinar a dinâmica do proteinograma sérico de bezerros holandeses submetidos a ingestão natural de colostro, foram utilizados 40 animais, a partir do nascimento até um ano de vida. Com exceção da fração protéica alfa globulina, as imunoglobulinas $\mathrm{G}$ e $\mathrm{M}$, a proteína total e as demais frações sofreram variações por influência de fatores etários. A proteína total aumentou a partir do nascimento $(4,11 \pm 0,30 \mathrm{~g} / \mathrm{dl})$ até 48 horas de vida $(6,62 \pm 1,26 \mathrm{~g} / \mathrm{dL})$, apresentando, a seguir, um decréscimo até o $30^{\circ}$ dia, elevando-se, novamente, até 1 ano de idade $(7,01 \pm 0,59 \mathrm{~g} / \mathrm{dL})$. A albumina foi a fração predominante no soro na fase que precedeu a ingestão do colostro, elevando-se a partir de 48 horas até 1 ano de idade. Os níveis da beta globulina aumentaram nas 96 horas posteriores à ingestão do colostro, apresentando, a partir de então, pequenas oscilações em sua concentração. Ao nascimento, os níveis da gama globulina e imunoglobulinas $\mathrm{G}$ e $\mathrm{M}$ foram mínimos $(0,09 \pm 0,09$, $20,20 \pm 24,57 \mathrm{mg} / \mathrm{dL}$ e $7,15 \pm 10,81 \mathrm{mg} / \mathrm{dL}$, respectivamente), aumentando, de seis a 24 horas após o acesso dos bezerros ao colostro. A seguir, esses valores diminuíram até 30 dias de idade, quando, então, elevaram-se gradativamente até 1 ano de vida $(2,14 \pm 1,07 \mathrm{mg} / \mathrm{dL}$ para a fração gama, 3373,81 $\pm 748,76 \mathrm{mg} / \mathrm{dL}$ para a lgG e 398,04 $\pm 83,92 \mathrm{mg} / \mathrm{dL}$ para a lgM). O nível de significância foi de $5 \%$.
\end{abstract}

Palavras-chave: bezerros; imunoglobulinas; imunidade passiva.

\begin{abstract}
In an attempt to determine proteinogram from newborn calves submitted to natural suckling of colostrum and from calves before and after parturition, 40 newborn Holstein calves were studied from birth to one year. Except for alpha globulin, the IgG, IgM total protein and other protein fractions changed with age. Total protein increased from birth to 48 hours of age; reduced until 30 days and finally increased until one year of age. Albumin was the principal protein of serum before colostrum intake, and after 48 hours of age albumin levels raised untill 365 days of life. There was a gradual increase in betaglobulins levels in the first 96 hours after colostrum intake, and after that there were little fluctuations in its levels. At the time of birth, levels of gamma globulin and immunoglobulins $G$ and $M$ were low, raising 6 to 24 hours after colostrum suckling. Then, those levels reduced until 30 days of life, when they began to increase slowly until one year of age.
\end{abstract}

Keywords: calves; immunoglobulins; passive immunity.

\section{Introdução}

As proteínas sempre foram consideradas constituintes essenciais de todas as células do organismo e correspondem a cerca de $18 \%$ do peso corporal dos animais (Dukes, 1988). Constituem um grupo de moléculas heterogêneas com várias características e funções (Jain, 1993). As proteínas são mantenedoras da pressão coloidosmótica (Kaneko e Cornelius, 1989). Outras funções das proteínas plasmáticas são: 1) ajudar a manter a pressão sangüínea normal, por contribuírem para a viscosidade sangüínea; 2) influenciar a estabilidade da suspensão de eritrócitos; 3) ajudar a regular o equilíbrio ácido-básico do sangue; 4) afetar a solubilidade de açúcares, lipídios e outras substâncias em solução no plasma e 5) transportar substâncias, como nutrientes (cálcio, fósforo, ferro, cobre, lipídios, vitaminas lipossolúveis e aminoácidos), hormônios (tireoxina, esteróides), colesterol, bilirrubina, heme e enzimas, dentre outras (Dukes, 1988).

Ao contrário de cães e gatos, que podem receber imunização passiva ainda quando do desenvolvimento intra-uterino, pela passagem direta de elementos constituintes do sangue materno (Brambell, 1958), a transferência de imunoglobulinas através da placenta não ocorre em bezerros e em outros animais, como cordeiros, leitões e potros (Radostits et al., 2000).

\footnotetext{
* Apoio financeiro FAPESP

** Curso de Medicina Veterinária da UNESP - campus de Araçatuba - Rua Clóvis Pestana 793, CEP 16050-680 - Araçatuba, SP (e-mail: leydsonf @fmva.unesp.br).

*** Faculdade de Medicina Veterinária e Zootecnia - USP - São Paulo, Capital.
} 
Niveis de 5,2 a 6,4 $\mathrm{g}$ de proteína total/dL foram observados em bezerros, logo após o nascimento até 15 dias de idade, por Kaneko e Mills (1970), enquanto Baroni et al. (1982) relataram teores médios de $7,07 \mathrm{~g} / \mathrm{dL}$, em animais com 4 a 8 meses de vida.

Borges (1997) observou um predomínio da fração albumina em bezerros, antes da ingestão do colostro, e um claro aumento da gama e beta globulinas, após o fornecimento do colostro.

As imunoglobulinas constituem um grupo de glicoproteínas presentes no soro e fluidos do organismo de todos os mamíferos, com funções de anticorpo. Eletroforeticamente, as imunoglobulinas apresentam uma faixa de heterogeneidade que se estende entre as frações alfa e gama globulinas do soro sangüíneo normal (Butler, 1969). Segundo MenanteauHorta et al. (1985), a meia-vida da imunoglobulina $\mathrm{G}$ em bovinos foi estimada em aproximadamente 20 dias. A imunoglobulina $M$ foi considerada a segunda em concentração no soro sangüíneo de bezerros e a principal imunoglobulina produzida na resposta imunitária primária, sendo mais eficiente do que a IgG na ativação de complemento e na opsonização de vírus.

Ishikawa e Konishi (1982) observaram concentrações séricas de IgM de grande magnitude 12 horas após o nascimento, ressaltando que tal fato, para a fração lgG, ocorreria às 30 horas de vida. Ao avaliar as concentrações séricas de imunoglobulinas em bezerros neonatos, Edwards (1982) encontrou valores médios de $5062 \mathrm{mg} / \mathrm{dl}$ para lgG e $259 \mathrm{mg} / \mathrm{dl}$ para IgM, em amostras séricas obtidas de 16 bezerros com 48 horas de vida. Jain (1993) descreveu que elevados níveis de imunoglobulinas séricas eram encontrados entre 18 e 30 horas após o nascimento, sendo que as frações $\operatorname{lgM}$ e $\lg A$ alcançavam os níveis máximos mais precocemente do que a fração IgG; a seguir, os teores de imuoglobulinas apresentavam uma diminuição gradativa, durante um período de uma a cinco semanas, na dependência da meia vida da imunoglobulina. Radostits et al. (2000) relataram que em bezerros os níveis de IgG declinavam suavemente, alcançando os valores mínimos por volta dos 60 dias de idade, em contraste com as variações das frações $\operatorname{lgM}$ e $\lg A$, que diminuíam mais rapidamente, alcançando os valores mínimos em torno dos 21 dias de idade.

O objetivo deste trabalho foi determinar a influência do fator etário na dinâmica do proteinograma sangüíneo de bezerros holandeses do nascimento até um ano de idade.

\section{Material e métodos}

Foram utilizados 40 animais da raça holandesa, sem distinção de sexo, os quais permaneceram com as mães por um período de 16 a 24 horas, ingerindo colostro ad libitum. A colheita de sangue foi realizada por punção jugular nos seguintes momentos : logo após o nascimento (antes da ingestão do colostro), às $6,12,24,48$ e 96 horas, como também aos $9,15,30,60,90$, 120,180 e 365 dias, após o nascimento.

A proteína total foi determinada pelo método do biureto segundo Gornall et al. (1949) modificado por Strufaldi (1987). A separação eletroforética das frações protéicas do soro foi efetuada segundo as técnicas descritas por Friedman (1961) e Kremers et al. (1967), citados por Strufaldi (1987).
A quantificação da lgG e IgM por imunodifusão foi feita segundo a técnica de Fahey e Mckelve (1965) e Mancini et al. (1965), respectivamente, utilizando-se placas de ágar (Binding Site Kit), incorporadas com anti-soros específicos.

Através dos dados obtidos foram determinados a média, mediana, desvio-padrão, coeficiente de variação em cada momento e para cada variável. Para verificar a existência de diferença estatística entre os momentos estudados em cada variável, foi realizada a análise de variância paramétrica com medidas repetidas (estatística $F$, Fischer-Snedecor), complementando-se com o teste de Tukey. No caso da IgM foi feita a análise de variância não paramétrica de Friedman ( $\mathrm{Fr})$. O nível de significância foi de $5 \%(Z a r, 1984)$.

\section{Resultados e discussão}

A proteína total do soro sangüíneo apresentou variações estatisticamente significativas, conseqüentes à influência dos fatores etários durante o desenvolvimento do animal até 1 ano de idade (Tabela 1), confirmando as observações de Braun (1946), Tennant et al. (1968), Kaneko e Mills (1970), Baroni et al. (1982), Fagliari et al. (1991), Jain (1993) e Borges (1997). Foi observada menor concentração de proteína total antes da ingestão do colostro $(4,11 \pm 0,30 \mathrm{~g} / \mathrm{dl})$, em valores semelhantes aos obtidos por Jain (1993), Fagliari et al. (1991) e Borges (1997). Todavia, cabe ressaltar que o referido valor foi menor do que o observado por Kaneko e Mills (1970), talvez pelo fato de terem sido utilizados no presente trabalho animais que não mamaram antes que a primeira colheita de sangue fosse realizada. Após a ingestão do colostro, houve um aumento progressivo nos níveis de proteína total até as 48 horas $(6,62 \pm 1,26 \mathrm{~g} / \mathrm{dL})$, como fora mencionado por Fagliari et al. (1991). Esses resultados declinaram, então, até os 30 dias de vida $(5,96 \pm 0,55 \mathrm{~g} / \mathrm{dL})$, a partir de quando, aumentaram, gradativamente, até 1 ano de idade $(7,01 \pm 0,59 \mathrm{~g} / \mathrm{dL})$.

A albumina demonstrou aumento gradativo e significativo, tendo sido igual a $2,63 \pm 0,28 \mathrm{~g} / \mathrm{dL}$ ao nascimento. Contudo, não houve influência evidente pela ingestão de colostro observada com 6,12 e 24 horas $(2,67 \pm 0,39,2,63 \pm 0,32$ e 2,61 \pm $0,35 \mathrm{~g} / \mathrm{dL}$, respectivamente). O valor máximo alcançado foi aos 180 dias de vida $(3,57 \pm 0,44 \mathrm{~g} / \mathrm{dL})$.

Imediatamente após o nascimento, ou seja, antes dos bezerros terem tido acesso ao colostro, foi observado valor para alfa globulina de 0,99 $\pm 0,25 \mathrm{~g} / \mathrm{dL}$ que sugere a capacidade de síntese desta fração protéica durante a vida fetal. Por isso, em concordância com Radostits et al. (2000), seria temeroso supor-se ocorrer influência da transferência placentária de imunidade passiva. Além disso, os valores de alfa globulina, não demonstrando variação estatística ao longo do período de observação, sugerem que essa fração globulínica não sofreu qualquer influência da ingestão do colostro. Tennant et al. (1968) também observaram uma menor concentração sérica de alfa globulina, antes de os bezerros terem acesso ao colostro.

A concentração de beta globulina variou de forma significativa. Os valores dessa fração protéica aumentaram seis horas após a ingestão do colostro, confirmando os resultados de Fagliari et al. (1991) e Borges (1997). Da mesma forma, o aumento da concentração da fração beta globulina sérica, observado desde a ingestão do colostro até nove dias de 
TABELA 1 - Proteinograma sérico de bezerros da raça holandesa com até 1 ano de idade. Araçatuba - SP, 1998

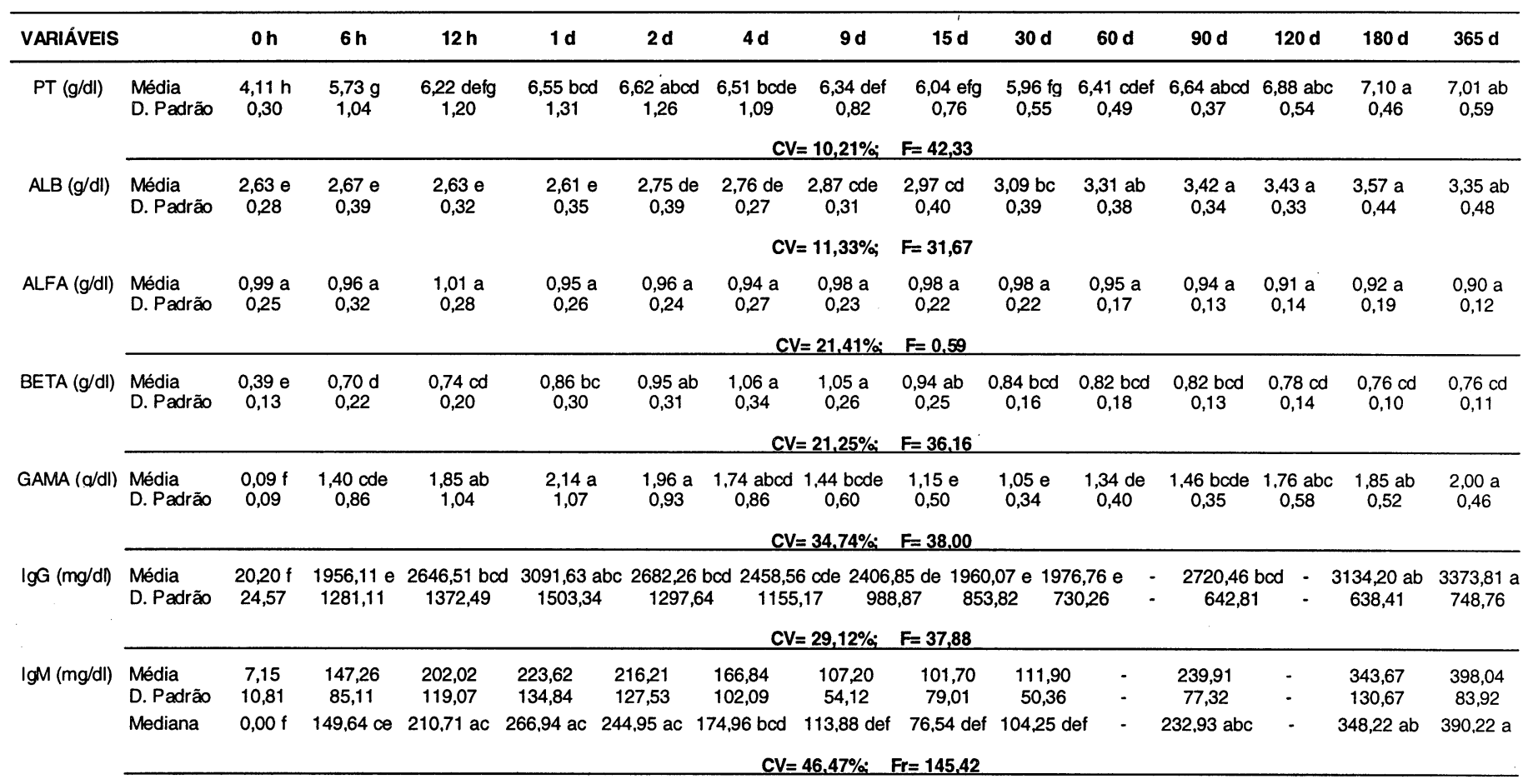

- PT: proteína total; ALB: albumina; ALFA: alfa globulina; BETA: beta globulina; GAMA: gama globulina; IgG: imunoglobulina G; IgM: imunoglobulina M.

- $\mathrm{CV}=$ coeficiente de variação; $\mathrm{F}=$ estatística $\mathrm{F}$, Fischer - Snedecor ; $\mathrm{Fr}=$ estatística de Friedman.

- Letras diferentes na mesma linha indicam diferenças entre os momentos ao nível de $5 \%$.

idade, seguido de estabilização, confirmou as conclusões apresentadas por Borges (1997).

Os bezerros neonatos apresentaram teor praticamente insignificante de gama globulina, com significativo aumento após a ingestão do colostro, confirmando as observações de Tennant et al. (1968), Lumsdem et al. (1980) e Borges (1997). A concentração da gama globulina atingiu um valor máximo às 24 horas de vida $(2,14 \pm 1,07 \mathrm{~g} / \mathrm{dL})$, indicando uma excelente absorção de imunoglobulinas, de acordo com as afirmações de Deutsch e Smith (1957), Brambell (1958), Tennant et al. (1968), Kruse (1970), Oyeniny e Hunter (1978), Bush e Stanley (1980), Zanetti et al. (1983) e Radostits et al. (2000). A partir de então, decresceu, gradativamente, apresentando valor mínimo aos 30 dias de vida $(1,05 \pm 0,34 \mathrm{~g} / \mathrm{dL})$. Isso pode ter ocorrido, pela existência de catabolismo mais intenso dos anticorpos maternos transferidos passivamente por absorção de proteínas do colostro, do que a síntese autógena de imunoglobulinas, não havendo, dessa forma, uma compensação proporcional às rápidas e intensas perdas observadas, conforme as afirmações de Logan et al. (1972), que destacaram a degradação das imunoglobulinas passivamente transferidas pela ingestão do colostro.

A partir dos 30 dias de idade, notou-se gradativo aumento da referida fração protéica, tendendo à estabilização após 120 dias, confirmando-se os valores obtidos e as oscilações demonstradas por Borges (1997).

Foi observado na presente pesquisa que os animais possuíam, no momento do nascimento, pequenas quantidades de anticorpos. A presença de imunoglobulinas $\mathrm{G}$ e $\mathrm{M}$ observada no sangue circulante de bezerros antes da ingestão de colostro pode ter sido em conseqüência de sua transferência do sangue materno através do cordão umbilical durante a gestação, como demonstrado por Edwards et al. (1988), ou pela ocorrência da incipiente síntese das mencionadas imunoglobulinas, ainda durante a vida fetal, como destacaram Husband et al. (1972) e Jain (1993).

Os valores médios mínimos tanto para IgG, de 20,20 \pm $24,57 \mathrm{mg} / \mathrm{dL}$, como para $\mathrm{lgM}$, de $7,15 \pm 10,81 \mathrm{mg} / \mathrm{dL}$, comprovam a deficiência de imunidade como havia sugerido Pennimpede (1987). Entretanto, seis horas após a ingestão de colostro, verificou-se significativo e abrupto aumento de ambas as imunoglobulinas $(1956,11 \pm 1281,11$ e $147,26 \pm$ $85,11 \mathrm{mg} / \mathrm{dL}$ respectivamente), atingindo, com 24 horas de vida, elevadas concentrações : $3091,63 \pm 1503,34 \mathrm{~g} / \mathrm{dL}$, para $\mathrm{lgG}$, e $223,62 \pm 134,84 \mathrm{~g} / \mathrm{dL}$, para IgM. Esses resultados confirmaram as observações de Husband et al. (1972), Matte et al. (1982), Susin et al. (1987), Jain (1993) e Borges (1997). A partir das 24 horas, constatou-se queda significativa dos níveis séricos da $\lg G$ e $\operatorname{lgM}, 1960,07 \pm 853,82$ e 101,76 \pm $79,01 \mathrm{mg} / \mathrm{dL}$, respectivamente, até os 15 dias de vida, quando, então, esses valores começaram novamente a aumentar, alcançando valores máximos aos 365 dias $(3373,81 \pm 748,76$ e $398,04 \pm 83,92 \mathrm{mg} / \mathrm{dL}$, respectivamente para $\mathrm{lgG}$ e $\mathrm{lgM}$ ), concordando com os relatos de Borges (1997). Ficou comprovado que a transferência de imunidade nos primeiros momentos de vida do bezerro deve-se, quase que exclusivamente, à absorção de imunoglobulinas presentes no colostro, como foi anteriormente sugerido por Ducluzeau (1983), White e Andrews (1986), Radostits et al. (1994) e Jan (1996). 


\section{Referências}

BARONI, D.S.F., MOLFI, A., BARONI, J.M. Teores normais de proteína plasmática total em bovinos jovens da raça holandesa preta e branca. Arquivos de Biologia e Tecnologia, v. 25, n. 2, p. 233-235, 1982.

BORGES, A. S. Avaliação da eficácia da administração de plasma por via intravenosa, como tratamento da falência de transferência de imunidade passiva em bezerros da raça Holandesa. São Paulo, 1997, 84p. Dissertação (Mestrado) - Faculdade de Medicina Veterinária e Zootecnia de São Paulo.

BRAMBELL, F.W.R. The passive immunity of the young mamal. Biological Revews, v. 33, p. 488 - 531, 1958.

BRAUN, W. Average levels of various constituents physical properties and formed elements of the blood of cows on pasture. American Journal of veterinary Research, v. 7, n. 25, p. 450-454, 1946.

BUSH, L.J., STANLEY, T.E. Absorption of colostral immunoglobulins in newborn calves. Journal of Dairy Science, v. 63 , n. 4, p. 672-860, 1980.

BUTLER, J.E. Bovine immunoglobulins: a review. Journal of Dairy Science, v. 52, n. 12, p.1895-909, 1969.

DEUTSCH, H.F., SMITH, V.R. Intestinal permeability to proteins in the newborn herbivore. American Journal of Physiology, v. 191, p. 271$276,1957$.

DUCLUZEAU, R. Implantation and development of the gut flora in the newborn animal. Annales de Recherches Vétérinaires, v. 14, n. 4, p. 354-359, 1983.

EDWARDS, S.A., BROOM, D.M., COLLIS, S.C. Factors affeting levels of passive immunity in dairy calves. British Veterinary Journal, v. 138, n.3, p.233-240, 1982.

FAHEY, J.L., McKELVEY E.M. Quantitative determination of serum immunoglobulins in antibody agar plates. The Journal of Immunology, v. 94, n. 1, p. 84, 1965.

FAGLIARI, J.J., OKUDA, H.T., PASSIPIERI, M., CURI, P.R. Valores de referência das proteínas séricas de bovinos Guzerá em diferentes faixas etárias. Arquivo Brasileiro de Medicina Veterinária e Zootecnia, v. 43, n. 1, p. 39-60, 1991.

FRIEDMAN H. S. A standardized procedure for serum proteín eletrophoresis on cellulose acetate membrane strips. Clinica Chimica Acta, v. 6, p. 775-781, 1961.

GORNALL, A.G., BARDAWILL, C.J., DAVID, M.M. Determination of serum proteín by means of biuret reaction. Journal of Biological Chemistry, v. 177, p. 751-766, 1949.

HUSBAND, J.J., BRANDON, M.R., LASCELLES, A.K. Absorption and endogenous production of immunoglobulins in calves. Journal of Biological, v.50, p.541-548, 1972.

ISHIKAWA, H., KONISHI, T. Changes in serum immunoglobulin concentrations of young calves. The Japanese Journal of Veterinary Science, v. 44, n. 4, p. 555 - 563, 1982.

JAIN, N.C. Essencial of veterinary hematology. Philadelphia: Lea \& Febiger, 1993. Cap. 7, p.133-158: Eritrocyte physiology and changes in disease.

JAN, C.L. Cellularcomponents of mamary secretions and neonatal immunity: A review. Veterinary Research, v. 27, n. 4/5, p. 403-417, 1996.
KANEKO, J.J., CORNELIUS, C.E. Clinical biochemistry of domestic animals. New York: Academic Press, 1989, 932 p.

KANEKO, J.J., MILLS, R. Hematological and blood chemical observation in neonatal normal and porphyric calves in early life. Cornell Veterinary, v. 60, n.1, p. $52-60,1970$.

KRUSE, V. Yield of colostrum and immunoglobulin in cattle at the first milking after parturition, Animal Production, v. 12, p. 619-626, 1970.

LOGAN, E. F., PENHALE, W. J., JONES, R. A. Changes in the serum immunoglobulin levels of colostrum fed calves during the first 12 weeks postpartum. Research Veterinary Science, v. 14, n. 3, p.394397, 1972.

LUMSDEN, J.H., MULLEN, K., ROWE, R. Hematology and biochemistry reference values for female holstein cattle. Canadian Journal of Comparative Medicine, v. 44, n. 1, p. 24-31, 1980.

MANCINI, G., CARBONARA, A.O., HEREMANS, J.F. Imunochemical quantitation of antigens by single radial immunodifusion. Imunochemistry, v. 2 , n. 3, p. 235-254, 1965.

MENANTEAU-HORTA, A.M., AMERS, T.R. , JOHNSON, D.W., et al. Effect of maternal antibody upon vaccination with infectious bovine rhinotracheitis and bovine virus diarrhea vaccines. Canadian Journal of Comparative Medicine, v. 49, n. 1, p.10, 1985.

MICUNOVIC, J., ZADMIK, T., NEMEC, M., JAZBEC, I. Gamma-globulin status of newborn calves. Veterinarske-Novice, v. 22, n. /8, p. 247251, 1996.

MORAES, M.P., WEIBLEN, R., SILVA, A.M., TOBIAS, F.L. Evolução da imunidade passiva em fêmeas bovinas da raça holandesa. Ciência Rural, v. 27, n. 3, p. 435-40, 1997.

OYENINY, O.O., HUNTER, A.G. Colostral constituents including immunoglobulins in the first thrre milkings postpartum. Journal of Dairy Science, v. 61, n. 1 , p. 44-48, 1978.

PENNIMPEDE, E.F.F., Immunidad neonatal en el ternero e immunoprofilaxis. Veterinária Argentina, v. 4, n. 31, p. 64-70, 1987.

RADOSTITS, O. M., GAY, C. C., BLOOD, D. C., HINCHCLIFF, K. W. Veterinary medicine. 9. ed. Saunders, 2000. 1877 p.

STRUFALDI, B. Prática de bioquímica clínica. São Paulo: Faculdade de Ciências Farmacêuticas da Universidade de São Paulo, 1987.399 p.

SUSIN, I., MACHADONETO, R., PIRES, A.V., PARKER, I.V. Imunoglobulina e proteínas total séricas em bezerros holandeses e mestiços. Revista da Sociedade Brasileira de Zootecnia, v. 16, n. 6, p. 588- 92, 1987.

TENNANT, B., HAROLD, D., REINA-GUERRA, M. LABEN, R.C., Neonatal alterations in serum gamma globulin levels of jersey and holstein-frisiean calves. American Journal of Veterinary Research, v. 30, n. 3, p. 345354, 1968.

WHITE, D.G., ANDREWS, A.H. Adequate concentrations of circulating colostral proteins for market calves. The Veterinary Record, v. 119, $n$. 8, p. 112-113, 1986.

ZANETTI, M.A., LUCCI, C.S., BIONDI, P., GAMBINI, L.B. Influência do método de administração de colostro sobre o nível sérico de imunoglobulina em bezerros. Arquivo Brasileiro de Medicina Veterinária e Zootecnia, v. 35, n. 2, p. 169-177, 1983.

ZAR, J.H. Biostatistical analysis. Englewood. Cliffs, Prentice-Hall, 1984. $718 \mathrm{p}$. 